\begin{tabular}{|c|c|c|c|c|c|}
\hline MUNIBE Antropologia-Arkeologia & $n^{\circ} 66$ & $5-21$ & DONOSTIA & 2015 & ISSN 1132-2217 • eISSN 2172-4555 \\
\hline
\end{tabular}

\title{
Un análisis tecno-funcional de los retocadores óseos musterienses del norte de la Península Ibérica, y su aplicación al estudio de los grupos neandertales
}

\author{
Techno-functional analysis of the mousterian bone retouchers from \\ Northern Iberia, and its application to the study of neanderthal groups
}

PALABRAS CLAVES: Huellas de uso, Paleolítico medio, Recursos, Tecnología, Utillaje.

GAKO-HITZAK: Erabilera-aztarnak, Erdi Paleolitoa, Baliabideak, Teknologia, Tresneria.

KEY WORDS: Use-wear, Middle Paleolithic, Resources, Technology, Tools.

Millán MOZOTA HOLGUERAS(1)

\section{RESUMEN}

En este trabajo abordamos el estudio de cuatro conjuntos de retocadores de hueso provenientes de otros tantos sitios musterienses del norte de la Península Ibérica: Peña Miel (La Rioja), Covalejos (Cantabria), Morín (Cantabria) y Prado Vargas (Burgos). A partir del análisis de 260 retocadores óseos, se presentan los resultados de un estudio que abarca los enfoques de la tafonomía, la morfometría y las huellas de uso. El objetivo es comprender el papel de los retocadores dentro de los sistemas de subsistencia de los neandertales. Nuestras observaciones demuestran que los retocadores de hueso se integran con diversas áreas productivas en la economía de esos grupos humanos, y no pueden ser considerados "herramientas de fortuna". Los conjuntos estudiados comparten algunas características estructurales, pero también hay un cierto grado de variabilidad. Esas variaciones se pueden explicar por los condicionamientos funcionales de los útiles, y en menor medida, por tradiciones o prácticas culturales de los distintos grupos.

\section{LABURPENA}

Lan honetan, Iberiar Penintsulako iparraldeko hainbat eremu mousteriarretatik etorritako hezurrei ukitua ematen dieten lau multzoren azterketa egin dugu: Peña Miel (Errioxa), Covalejos (Kantabria), Morín (Kantabria) eta Prado Vargas (Burgos). 260 hezur ukitu-emaileren azterketaren ostean, tafonomiaren, morfometriaren eta erabilera-aztarnen ikuspegiak lantzen dituen azterketaren emaitzak aurkezten dira. Neandertalgo gizakiek bizirauteko sistemen baitan ukitu-emaileen zeregina ulertzea da helburua. Gure behaketek erakusten dute hezur ukituemaileak hainbat ekoizpen-arlorekin txertatzen direla giza talde horien ekonomian, eta ezin dira "halabeharrezko tresnatzat" hartu. Aztertutako multzoek egiturazko hainbat ezaugarri partekatzen dituzte, baina aldagarritasun maila bat ere badago. Aldaketa horiek tresnen baldintzapen funtzionalek azal ditzakete, eta neurri txikiagoan, taldeen tradizio edo praktika kulturalek.

\section{ABSTRACT}

In this paper, we analyze four assemblages of bone retouchers that were collected on an equal number of Mousterian sites located in northern Iberia: Peña Miel (La Rioja), Covalejos (Cantabria), Morín (Cantabria) and Prado Vargas (Burgos). From the analysis of 260 bone retouchers, the results of a study covering taphonomical, morphometrics and use-wear approaches are presented. We study all the archaeological materials from both a quantitative and qualitative perspective, but we do not limit our inferential tools to archaeological artifacts: our technical analysis is also based on an extended experimental program that comprised 177 experiments of retouch. The ultimate goal of our holistic approach is to understand the retouchers' role within the subsistence systems of the neanderthals. The study, together with the contextual archaeological information, allows us to explain how the bone retouchers integrate with various productive areas of neanderthal economy. We can confirm that these tools become key pieces of economic management, bridging different subsistence areas. In particular, the retouchers highlight a bridge between two key areas: the collection and management of animal resources, and the management of mineral resources (stone tools). Then, while retouchers are not very elaborated tools, they cannot be considered "fortune" or adhoc tools, because the strategies for the production and management of these valuable bone implements are not improvised or left to chance. They respond to a series of criteria that are common to the different studied assemblages. These shared features suggest a structural similarity between the groups when configuring the management of their tools. But at the same time, at least two aspects of variability were found: (1) a flexibility in the performed tasks, which probably has to do with the specific demands of lithic retouch; and (2) some diversity in how to maintain and refit the bone tools, which may be related to cultural practices or traditions of the groups.

(1) Department of Archaeology and Anthropology, Institución Milá y Fontanals, CSIC. C/Egipcíaques, 15. Barcelona. E-08001 (ESPAÑA). Phone number: +34934423489. E-mail: millanm@imf.csic.es 


\section{1.- INTRODUCCIÓN}

La comunidad investigadora ha estudiado las herramientas de hueso del Paleolítico Medio desde perspectivas muy diferentes en los últimos dos siglos. En general, dichas aproximaciones han seguido la evolución de las diferentes escuelas de pensamiento y teorías arqueológicas que se han sucedido en la historia de la disciplina. Desde esa perspectiva, las visiones que hoy se pueden considerar tradicionales definen estas herramientas como útiles "menos elaborados" (PATOU-MATHIS, 1999) o bien "improvisados" (CHASE, 1990). En general, estas conceptualizaciones se hacen por comparación con el utillaje de etapas posteriores y, en particular, con las industrias del Paleolítico superior europeo o la MSA africana. Frente a ello, a finales del siglo XX se comienzan a proponer otras hipótesis y explicaciones, que sugieren la existencia de procesos de cierta complejidad en la obtención y uso de las herramientas óseas durante el Paleolítico Medio (GAUDZINSKI, 1999). Finalmente, estudios recientes sugieren la existencia de herramientas más elaboradas, así como de útiles especializados para llevar a cabo determinadas tareas (SORESSI et al. 2013).

Hay un tipo de útil en hueso que es característico del Paleolítico Medio y está presente en numerosos yacimientos de toda Eurasia: el retocador óseo. Concurre el hecho de que, con cierta frecuencia, dichas herramientas aparecen en forma de conjuntos numéricamente muy abundantes en los contextos arqueológicos. En particular, el subtipo que más abunda en los yacimientos musterienses europeos es el denominado retocador en esquirla diafisaria de ungulado.

Los retocadores de hueso se han encontrado en contextos musterienses desde finales del siglo XIX (HENRI-MARTIN, 1906; PATOU-MATHIS, 2002). Además, numerosos trabajos de los últimos años han puesto de relevancia su importancia en los conjuntos arqueológicos recientemente excavados o revisados (ABRAMS et al., 2014; DAUJEARD et al., 2014; ROSELL et al., 2014). Su papel en los sistemas económicos de los grupos humanos del Paleolítico Medio, sin embargo, ha recibido algo menos de atención.

En este trabajo presentamos el análisis de cuatro conjuntos de retocadores que provienen de yacimientos paleolíticos. Dichos sitios arqueológicos están ubicados en diferentes puntos del norte de la Península Ibérica (figura 1). En todos los casos los conjuntos estaban formados por un cierto número de retocadores, siempre en esquirlas de hueso de macromamíferos. Los depósitos arqueológicos asociados a estos útiles contenían herramientas líticas musterienses, así como otras evidencias inequívocas de ocupaciones de grupos neandertales del Paleolítico Medio.

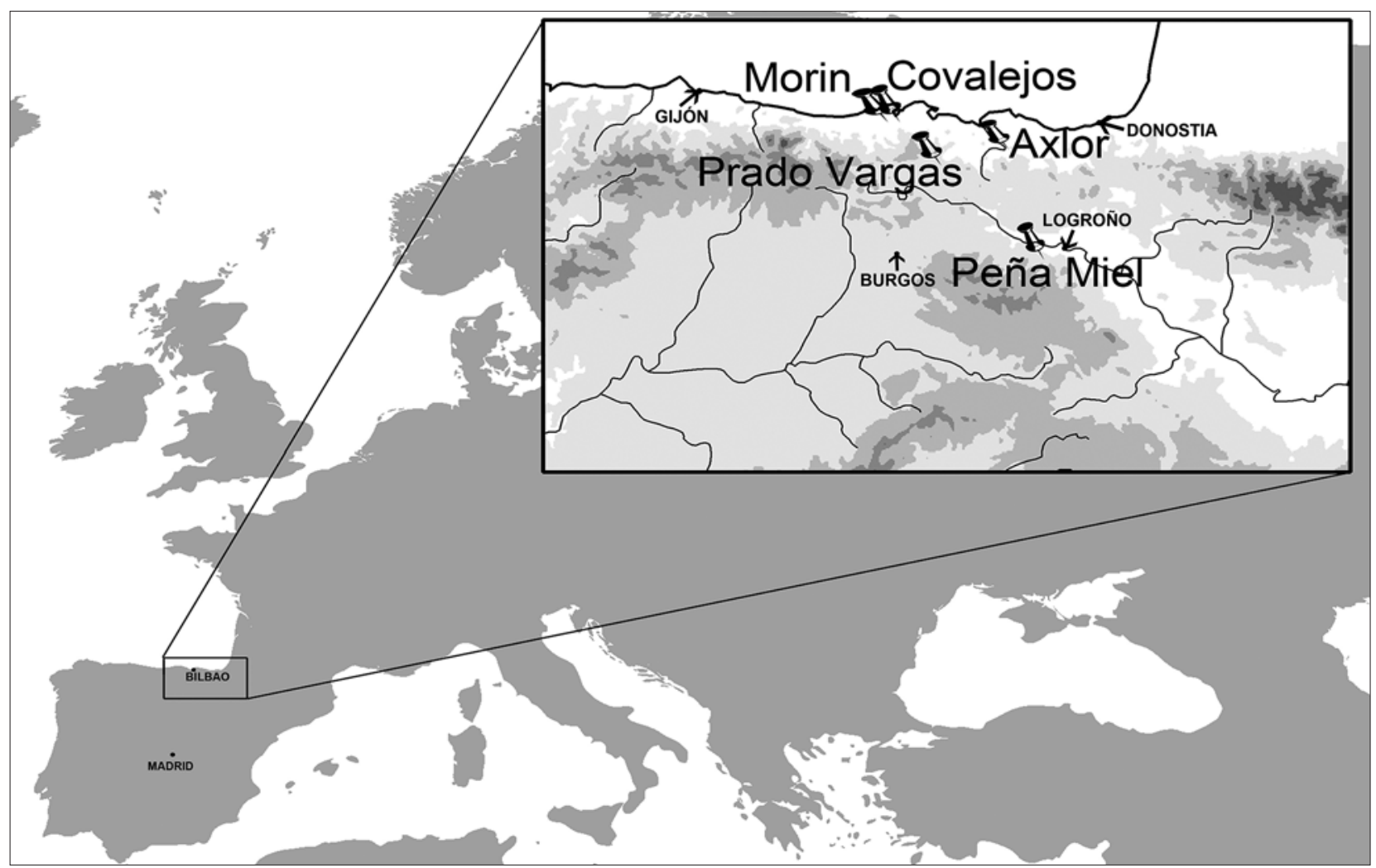

Fig. 1. Localización de los yacimientos musterienses con retocadores que han sido analizados en este trabajo. Se incluye el abrigo de Axlor, al citarse en el texto algunos datos de ese yacimiento, para la comparación con los sitios estudiados / Location of Mousterian sites with bone retouchers studied in this work. It includes the Axlor site, as some data from this place are cited in the text, for comparisons. 


\section{2.- MATERIALES Y MÉTODOS}

\subsection{Materiales:}

\section{Yacimientos y conjuntos arqueológicos}

La cueva de Peña Miel (Nieva de Cameros, La Rioja) contiene importantes depósitos paleolíticos, que fueron descubiertos a mediados del siglo XIX durante una actuación pionera de LARTET (1866). Sin embargo, no se realizó una excavación con metodología moderna hasta los años ochenta del siglo XX (UTRILLA y MONTES, 1987). Los materiales estudiados pertenecen al estrato arqueológico Nivel G, en el cual se hallaron numerosos utensilios líticos musterienses. No hay datación absoluta para este nivel, pero sus excavadoras propusieron una fecha en torno a 50.000 BP, a partir de la sedimentología, los datos faunísticos y una fecha de radiocarbono para una capa más reciente (MONTES et al., 2001). El conjunto estudiado por nosotros se compone de 162 retocadores de hueso, algunos más de los fueron publicados tras las excavaciones (BARANDIARÁN, 1987).

La cueva de Covalejos (Piélagos, Cantabria) también tiene un importante depósito paleolítico, que fue excavado a finales de los años noventa del siglo XX (SANGUINO y MONTES BARQUÍN, 2005). En este caso, los materiales estudiados provienen del estrato arqueológico Nivel K. En dicha capa se documentaron materiales líticos musterienses, pero no existe una datación absoluta de la misma. Sin embargo, las dataciones de los niveles superiores e inferiores de la secuencia proporcionan "terminus ante quem" ( $>45.000$ BP no calibrado C-14, Gra-33812, MAROTO et al., 2012) y "terminus post quem" (91.857 +/- 4000 BP Uh, SANGUINO y MONTES BARQUÍN, 2005). En la revisión de los materiales de la excavación hallamos 59 retocadores óseos, que han sido estudiados en este trabajo.

Cueva Morín es un sitio clásico de la arqueología paleolítica del norte de la Península Ibérica. La cavidad se sitúa en Villanueva de Villaescusa (Cantabria), y ha sido excavada desde 1910 (VEGA DE SELLA, 1921), pero sólo fue estudiada en profundidad a partir de los años sesenta (FREEMAN, 1971). Los materiales aquí analizados provienen del Nivel 17. Dicho estrato arqueológico contiene materiales líticos musterienses, pero no tiene una datación absoluta, ni existe un marco cronológico fiable para esa parte de la secuencia. Por lo tanto, no es posible proponer una fecha específica para la capa, aunque debe adscribirse sin dudas al Paleolítico Medio. En este caso el conjunto óseo estudiado se compone de 24 retocadores. Dicha muestra está probablemente sesgada por una recogida selectiva de los materiales durante la excavación, y también debido a problemas relacionados con la gestión y conservación patrimonial y museística (YRAVEDRA y GÓMEZ CASTANEDO, 2011; MOZOTA 2012: 276-278).

Por último, la cueva de Prado Vargas (Cornejo, Burgos) contiene un depósito Paleolítico excavado en 1986 y 2006 (NAVAZO et al., 2005; NAVAZO, 2010). El material estudiado proviene del estrato arqueológico Nivel 4, que contiene artefactos musterienses. La capa está fechada en
46.200 BP por racemización de aminoácidos (NAVAZO et al., 2005). La revisión de los materiales de la excavación proporcionó 15 retocadores, que han sido estudiados en este trabajo.

\subsection{Métodos}

El análisis de los procesos tafonómicos es crítico para comprender y explicar las rutas diagenéticas que han llevado a la formación de los depósitos arqueológicos. También es necesario para el especialista el poder discriminar aquellas alteraciones que no corresponden a la fabricación y uso de las herramientas. Del mismo modo, es vital estudiar las modificaciones que alteran y eventualmente destruyen los estigmas tecnológicos y funcionales. Por todas esas razones hemos realizado un detallado análisis tafonómico previo al estudio tecnológico y funcional de los útiles óseos aquí presentados.

En primer lugar, debemos explicar que nuestra hipótesis a priori ha sido considerar que las huellas de percusión, corte y raspado que observamos en los útiles (de evidente origen antrópico) están relacionadas con actividades de carnicería. Esas huellas son bien conocidas y han sido estudiadas en profundidad en la literatura científica relevante (LYMAN, 1994: 294-354). Sólo en los casos en los que durante el análisis detectamos indicios que ponían en duda dicha atribución hemos considerado posibilidades técnicas alternativas para explicar esas huellas o marcas en particular.

Para el análisis tafonómico observamos los materiales con bajos (5x-50x) y altos aumentos (50x-500x). Nuestro objetivo específico era documentar y analizar: (1) los diferentes estigmas antrópicos, limitando el estudio en esta fase a las marcas no vinculadas con el uso; (2) las modificaciones producidas por agentes no antrópicos, como los carnívoros; y (3) las alteraciones relacionadas con los procesos de sedimentación y los fenómenos postdeposicionales.

El método de observación y registro fue concebido para incluir diferentes aspectos típicos de la diagénesis en sitios arqueológicos, a saber: la tafonomía de vertebrados (LYMAN, 1994), la fragmentación antropogénica del hueso (OUTRAM, 2001, 2002; ALCÁNTARA et al., 2006) y las alteraciones de la superficie ósea (BLUMENSCHINE, MAREAN y CAPALDO, 1996; D'ERRICO y VILLA, 1997).

En el apartado del estudio tecnológico, el análisis se orientó a obtener datos concretos que permitieran realizar inferencias significativas sobre cómo estos objetos se convirtieron en herramientas. Nuestro estudio trata por tanto de comprender la selección de los soportes en bruto, a partir de la materia prima potencialmente disponible en cada lugar (es decir, los restos de la fauna consumida). Y también estudiamos los posibles casos de modificación de dichos soportes en bruto. Para ello, hemos utilizado información anatómica y taxonómica, junto con un análisis morfométrico de los útiles (figura 2). 


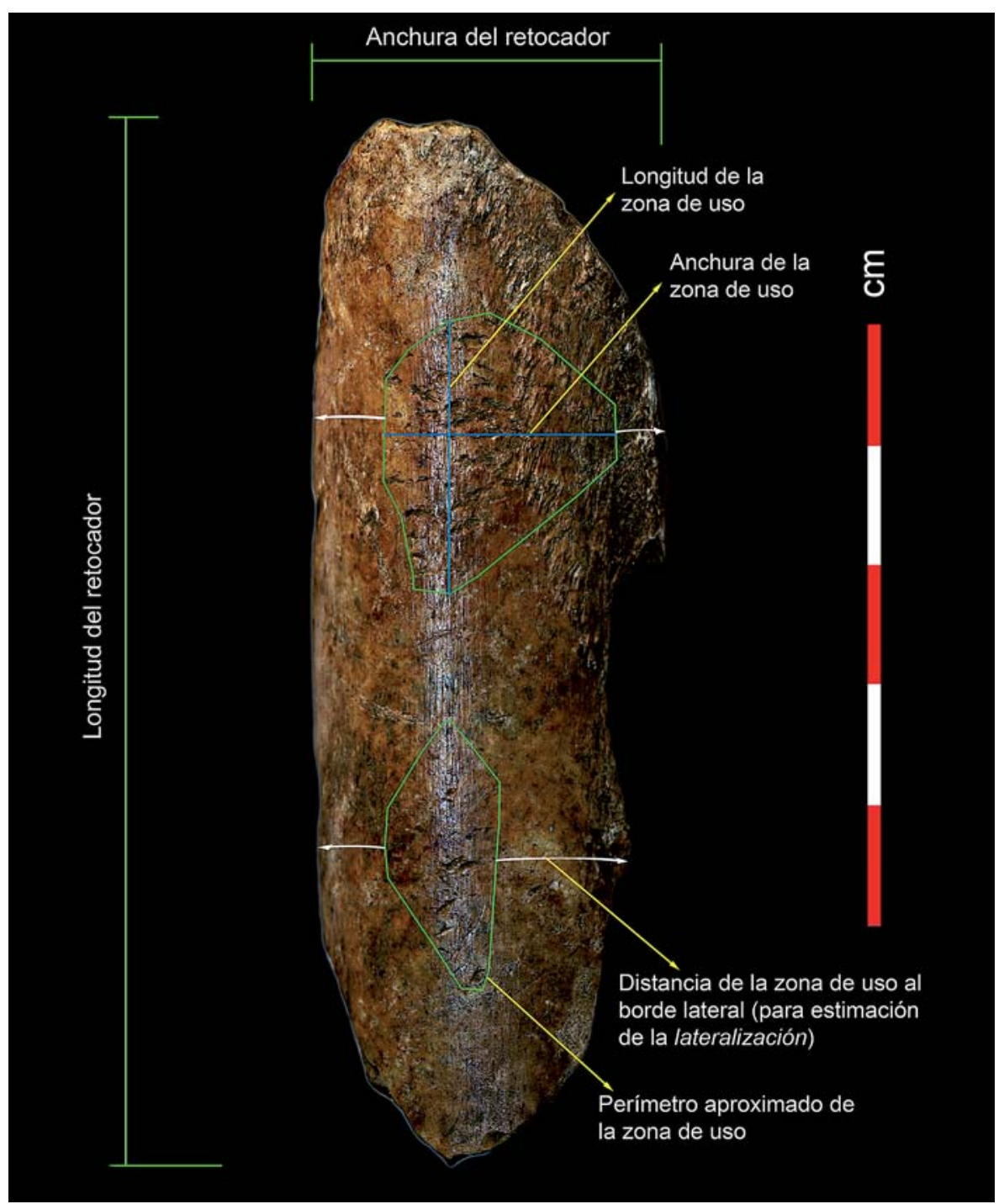

Fig. 2. Principales dimensiones morfométricas y medidas realizadas para el estudio de los soportes de los retocadores. La imagen corresponde a uno de los retocadores de hueso estudiados de Peña Miel Nivel G. / Principales dimensiones morfométricas y medidas realizadas para el estudio de los soportes de los retocadores. La imagen corresponde a uno de los retocadores de hueso estudiados de Peña Miel Nivel G.

Además, para comprender mejor las estrategias de fragmentación de los huesos de fauna y la recogida de los soportes entre dichos restos, diseñamos un programa experimental adecuado a la pregunta. Esto se ha combinado con datos y estimaciones anatómicas y taxonómicas, obtenidas de las publicaciones de los especialistas que estudiaron los restos de fauna de cada yacimiento.

El detalle específico del programa experimental de selección de soportes ya ha sido publicado en trabajos anteriores (MOZOTA, 2012: 49-73; MOZOTA, 2013). No obstante, a continuación proporcionamos un breve resumen de la metodología y los resultados de dicho programa experimental.

Se fracturaron un total de 38 huesos largos (incluyendo metápodos) de ungulados de talla grande y media, usando para ello herramientas macro-líticas. Dichas he- rramientas estaban fabricadas sobre diferentes materias primas, con tamaños y pesos variados (MOZOTA, 2013) pero en todos los casos se trataba de litologías del norte de la Península Ibérica. Y tenían morfologías afines a las representadas en el registro arqueológico de Paleolítico Medio de la región.

Las variables independientes en el análisis de la fragmentación ósea fueron las siguientes: Taxón, origen anatómico, frescura del hueso y estrategia general de fracturación. Esta última variable se caracterizó por dos estrategias opuestas: (1) la fracturación "Ad hoc" y recogida improvisada de soportes; y (2) un proceso de fracturación concebido para obtener el máximo número posible de herramientas aptas para el retoque. El objetivo principal de esta parte del programa experimental era comprender en qué forma las variables independientes (como el es- 
tado del hueso o la estrategia de fracturación) afectan a las variables dependientes: los tipos de fractura producidos, el tamaño de los soportes obtenidos, y el número de útiles recogidos por elemento óseo (en relación a la cantidad de astillas y otros restos no utilizables).

Gracias a todos esos datos experimentales y a las conclusiones obtenidas de los mismos, ha sido posible alcanzar, en el presente trabajo, un cierto grado de comprensión de las estrategias que pudieron articular los grupos neandertales de cara a la obtención de los soportes óseos para su utillaje.

En cuanto al apartado funcional, se analizaron las huellas de uso siguiendo una metodología igualmente publicada (MOZOTA 2012: 74-95; MOZOTA, 2013) cuyos aspectos esenciales se resumen en los siguientes párrafos.

Dicha metodología se asienta en una larga tradición de estudio de huellas de uso sobre retocadores óseos, en donde tienen especial relevancia las obras de SEMENOV (1964), RIGAUD (1977, 2007), VICENT (1993), ARMAND y DELAGNES (1998), PATOU-MATHIS (2002) y JÉQUIER et al. (2012).

La base de nuestra metodología es un programa experimental específico centrado en las tareas de retoque, que comprende 177 experimentos con soportes óseos, usados para trabajar sobre distintas materias líticas.

La primera cuestión abordada en nuestro estudio fue la posición y lateralización de la zona de uso. El experimentador era un sujeto diestro que realizó varios tipos de retoque por percusión y por presión. Al estudiar los resultados de los experimentos, se detectaron patrones claros y recurrentes en la morfología de las zonas de uso y en su lateralización sobre el conjunto del soporte. En las tareas por percusión, comprobamos que tienden a formarse zonas de uso ovales, con el diámetro mayor en sentido longitudinal. Por el contrario, las tareas de retoque de presión producen zonas de uso más redondeadas, casi circulares.

En cuanto a la lateralización de las áreas activas, al analizar las tareas por percusión se aprecia un patrón recurrente: Considerando los útiles en su conjunto, a partir de estadísticos centrales, se documenta una muy ligera desviación de la zona de uso hacia el lado derecho del soporte. Esto es cierto para el total de la muestra estudiada, pero también para todos los sub-conjuntos que establecimos en los experimentos por percusión, lo cual fortalece notablemente dicha regularidad, y su significación. Por otro lado, las tareas de retoque por presión también muestran una pequeña lateralización de la zona de uso, de disposición opuesta: hacia el lado izquierdo del soporte. No obstante los experimentos por presión fueron menos numerosos, y esa regularidad no se cumplía en todos y cada uno de los sub-conjuntos establecidos para el retoque por presión.

En este punto es importante señalar que la ausencia de retoque por presión en el Paleolítico Medio es un tópico de las disciplinas arqueológicas, que se repite con ubicuidad en la literatura científica, aunque nunca ha sido abordado desde un punto de vista demostrativo. En ese sentido, nuestro trabajo proporciona un marco para demostrar o no dicha ausencia, desde el análisis funcional de los retocadores óseos. No obstante, cabe destacar que, dentro de los sitios musterienses aquí estudiados, no se ha documentado la presencia de retoque por presión.

En cuanto al análisis de las huellas de uso en sentido estricto, el programa experimental se diseñó para documentar una serie de variables independientes: frescura de hueso, tareas específicas de retoque, intensidad de uso, y por último, las materias primas líticas sobre las que se trabajó con los retocadores. Gracias a los resultados experimentales, sabemos que cada variable tiene efectos particulares en los estigmas o huellas de uso observables a posteriori sobre las superficies óseas.

En este punto, es importante explicar que dichas huellas de uso se han clasificado en una tipología limitada de estigmas unívocos (Figura 3): Impresiones lineales, Impresiones triedro, Estrías y Desconchados masivos. Todos los estigmas fueron observados, contados, descritos y medidos. Y, a continuación, se analizaron aspectos como su ratio presencia/ausencia, su número total, y varios estadísticos derivados. Dichos datos fueron estudiados en relación a las variables independientes que antes citamos, para establecer relaciones de causalidad.

La información resultante nos permite utilizar este referente experimental para estudiar las huellas de uso en los conjuntos arqueológicos. Y, en último término, para realizar inferencias sobre el uso de este tipo de útiles en la Prehistoria.

En concreto, nos permite inferir con ciertas garantías el tipo de retoque realizado, su intensidad de uso, la materia lítica trabajada o el estado del hueso cuando se utilizó. Aún así, no podemos obviar que existe un cierto grado de yuxtaposición en los efectos de las variables - por el momento insoslayable. Esto significa que, en algunos aspectos, sólo se pueden proponer hipótesis razonables o explicaciones parciales de los fenómenos observados.

Además, la comparación cualitativa de las muestras experimentales y arqueológicas nos permite hacer otras inferencias sobre cuestiones tecnológicas y de uso. Por ejemplo, sobre la existencia de reacondicionamientos de las áreas activas. Dichos reacondicionamientos fueron detectados a partir de la observación microscópica de los estigmas de uso, y en particular su desgaste, distribución, superposición y/o yuxtaposición.

Para este trabajo en particular, el criterio para determinar si se produjo un reacondicionamiento de la zona de uso ha sido el siguiente: es necesario que se documente una sucesión de estigmas, de más antiguos a más recientes: (1) Estigmas de retoque, casi completamente borrados, (2) marcas de raspado que cubren a los anteriores, y (3) las huellas de retoque por encima de las marcas del raspado. Como puede imaginarse, esta sucesión es extremadamente difícil de documentar dentro de las muestras arqueológicas. La alteración tafonómica más mínima de la superficie ósea puede hacer imposible detectar tal sucesión de estigmas. 

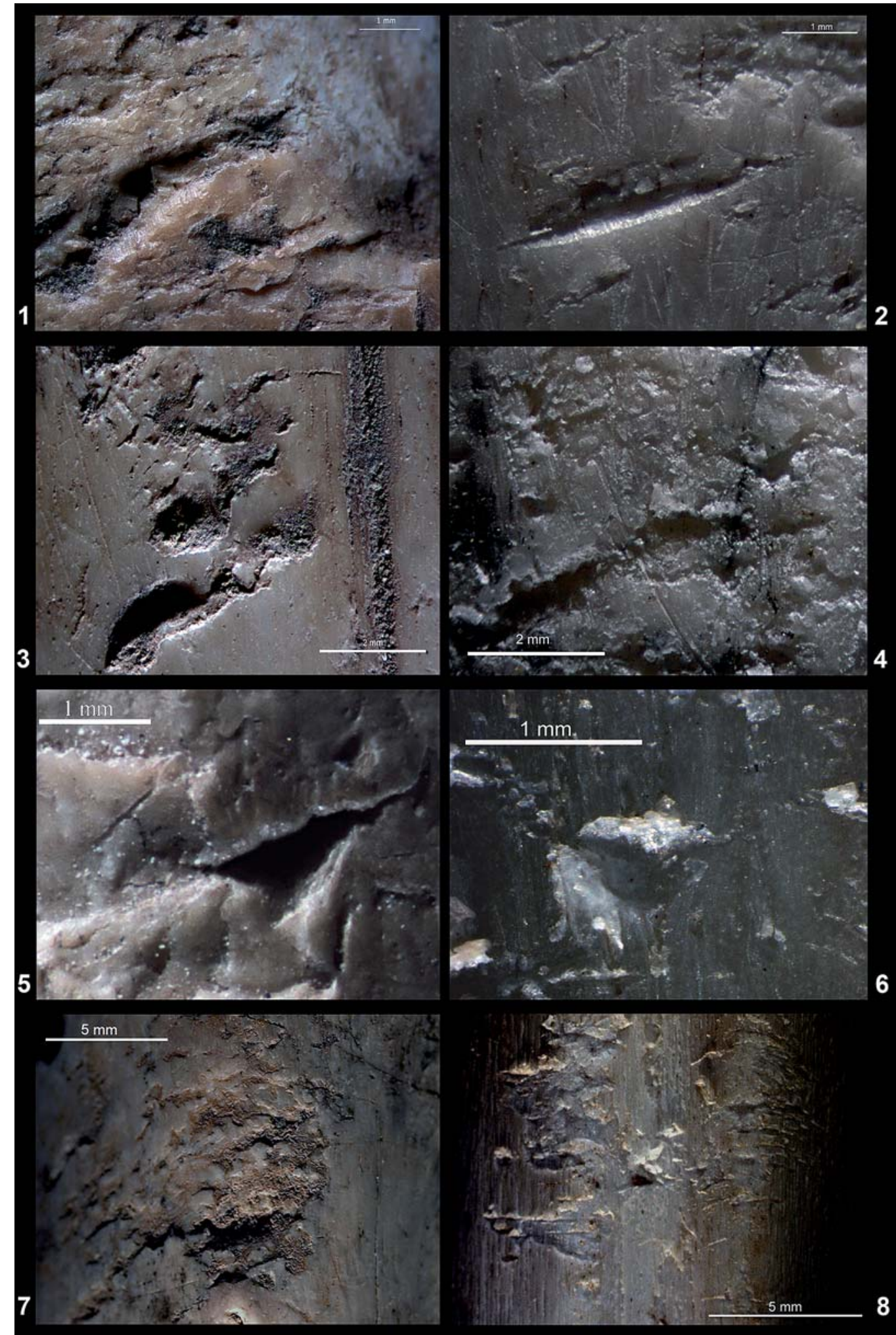

Fig. 3. Huellas de uso en retocadores arqueológicos y experimentales. 1: Detalle de las impresiones lineales, Peña Miel Nivel G. 2: Detalle de las impresiones lineales, muestra experimental. 3: Estrías e impresiones lineales en asociación directa, Peña Miel Nivel G. 4: Estrías e impresiones lineales en asociación directa muestra experimental. 5: Impresión triedro, Peña Miel Nivel G. 6: Impresión triedro, muestra experimental. 7: Desconchado masivo, Prado Vargas Nivel 4. 8: Desconchado masivo, muestra experimental / Traces of use in archaeological and experimental bone retouchers. 1: Linear impression detail, Peña Miel Level G. 2: Linear impression detail, experimental sample. 3: Striations and linear impressions in direct association, Peña Miel Level G. 4: Striations and linear impressions in direct association, experimental sample. 5: Trihedral impression, Peña Miel Level G. 6. Trihedral impression, experimental sample. 7: Widespread chipping, Prado Vargas Level 4. Widespread chipping, experimental sample. 


\section{3.- RESULTADOS}

\subsection{Tafonomía}

\begin{tabular}{|c|c|c|c|c|}
\hline \multicolumn{3}{|c|}{ Tipo de alteración tafonómica } & Número de casos & Índice de presencia \\
\hline \multicolumn{5}{|c|}{ Peña Miel Nivel G (n=162) } \\
\hline \multirow{6}{*}{ Deposicional } & \multirow{4}{*}{ Antrópico } & Hueso quemado & 2 & 0.12 \\
\hline & & Estigmas percusión & 100 & 0.613 \\
\hline & & Estigmas corte & 70 & 0.429 \\
\hline & & Huellas de rapado & 34 & 0.208 \\
\hline & Indeterminado & Trampling extensivo & 0 & 0.0 \\
\hline & Carnívoro & Mordeduras y roídos & 1 & 0.006 \\
\hline \multirow{3}{*}{ Postdeposicional } & \multicolumn{2}{|c|}{ Residuos minerales adheridos } & 74 & 0.453 \\
\hline & \multicolumn{2}{|c|}{ Fractura en hueso seco } & 1 & 0.006 \\
\hline & \multicolumn{2}{|c|}{ Huesos rodados y redondeados } & 0 & 0.0 \\
\hline \multicolumn{5}{|c|}{ Covalejos Nivel K ( $n=59)$} \\
\hline \multirow[t]{6}{*}{ Deposicional } & Antrópico & Hueso quemado & 0 & 0.0 \\
\hline & & Estigmas percusión & 33 & 0.559 \\
\hline & & Estigmas corte & 21 & 0.355 \\
\hline & & Huellas de rapado & 7 & 0.11 \\
\hline & Indeterminado & Trampling extensivo & 0 & 0.0 \\
\hline & Carnívoro & Mordeduras y roídos & 1 & 0.016 \\
\hline \multirow[t]{3}{*}{ Postdeposicional } & \multicolumn{2}{|c|}{ Residuos minerales adheridos } & 21 & 0.355 \\
\hline & \multicolumn{2}{|c|}{ Fractura en hueso seco } & 1 & 0.016 \\
\hline & \multicolumn{2}{|c|}{ Huesos rodados y redondeados } & 0 & 0.0 \\
\hline \multicolumn{5}{|c|}{ Morín Nivel 17 (n=24) } \\
\hline \multirow[t]{6}{*}{ Deposicional } & Antrópico & Hueso quemado & 0 & 0.0 \\
\hline & & Estigmas percusión & 10 & 0.416 \\
\hline & & Estigmas corte & 9 & 0.37 \\
\hline & & Huellas de rapado & 3 & 0.125 \\
\hline & Indeterminado & Trampling extensivo & 2 & 0.083 \\
\hline & Carnívoro & Mordeduras y roídos & 1 & 0.041 \\
\hline \multirow[t]{3}{*}{ Postdeposicional } & \multicolumn{2}{|c|}{ Residuos minerales adheridos } & 14 & 0.583 \\
\hline & \multicolumn{2}{|c|}{ Fractura en hueso seco } & 2 & 0.083 \\
\hline & \multicolumn{2}{|c|}{ Huesos rodados y redondeados } & 1 & 0.041 \\
\hline \multicolumn{5}{|c|}{ Prado Vargas Nivel 4 ( $n=15)$} \\
\hline \multirow[t]{6}{*}{ Deposicional } & Antrópico & Hueso quemado & 0 & 0.0 \\
\hline & & Estigmas percusión & 12 & 0.8 \\
\hline & & Estigmas corte & 12 & 0.8 \\
\hline & & Huellas de rapado & 2 & 0.133 \\
\hline & Indeterminado & Trampling extensivo & 3 & 0.2 \\
\hline & Carnívoro & Mordeduras y roídos & 0 & 0.0 \\
\hline \multirow[t]{3}{*}{ Postdeposicional } & \multicolumn{2}{|c|}{ Residuos minerales adheridos } & 4 & 0.266 \\
\hline & \multicolumn{2}{|c|}{ Fractura en hueso seco } & 0 & 0.0 \\
\hline & \multicolumn{2}{|c|}{ Huesos rodados y redondeados } & 1 & 0.066 \\
\hline
\end{tabular}

Tabla 1: Resultados del análisis tafonómico (conjuntos de retocadores de Peña Miel, Morín, Covalejos y Prado Vargas) / Results of taphonomic analysis (retoucher assemblages from Peña Miel, Morín, Covalejos and Prado Vargas). 
Nuestra primera tabla muestra los estigmas tafonómicos organizados por categorías amplias y auto-explicativas. En el apartado de las alteraciones deposicionales, la primera observación relevante es la ausencia de huesos quemados (con la excepción de Peña Miel Nivel G, donde hay dos casos). Hay abundantes marcas antrópicas de carnicería en todos los conjuntos: incisiones de corte, huellas de raspado y marcas de percusión para fracturar el hueso. Estas marcas están algo menos presentes en Morín 17, y por el contrario son más frecuentes en Prado Vargas 4.

La presencia de marcas de carnívoros es muy escasa en general: va desde una presencia muy baja (Morín Nivel 17) hasta inexistente (Prado Vargas Nivel 4). Por otro lado, la incidencia de estigmas postdeposicionales varía entre los distintos conjuntos, en función de la historia tafonómica del yacimiento, pero en su mayor parte son modificaciones relacionadas con los procesos kársticos y sedimentarios. La mayor parte de las alteraciones en esta categoría son adherencias de calcita y/o de óxidos de manganeso sobre la superficie del hueso.

\subsection{Análisis de los soportes}

Para estudiar los datos morfométricos de los soportes hemos utilizado una selección de retocadores completos (se excluyeron los fragmentarios). La figura 4 es un gráfico que muestra como se agrupa la distribución por tamaños (Longitud y Anchura) de los soportes, con una variabilidad relativamente baja. La línea que marca el intervalo de confianza del conjunto permite diferenciar como valores extremos a una docena de retocadores. En este subgrupo destacaría la presencia de varios retocadores de Morín Nivel 17 (4 de los 22 soportes de dicho nivel).

La mayor parte de las herramientas tienen 15-40 $\mathrm{mm}$ de ancho y 45-120 mm de largo, con una tendencia a agruparse alrededor de los valores medios de esas dimensiones. Un hecho de especial relevancia es que los valores medios de Longitud y Anchura son muy similares entre los tres de los sitios: Peña Miel Nivel G, Prado Vargas Nivel 4 y Nivel Covalejos K. En el caso de Morín Nivel 17 el tamaño de los soportes es significativamente más grande. Esta característica podría estar relacionada con el origen taxonómico (Bos/Bison sp. y Equus sp.) en el yacimiento de Morín. Sin embargo, cabe recordar la naturaleza sesgada de la muestra del Morín, debido a dos problemas: (1) la recogida selectiva de los materiales durante las excavaciones, (2) un problema de conservación importante de tipo patrimonialmuseístico (YRAVEDRA Y GÓMEZ CASTANEDO, 2011; MOZOTA. 2012: 276-278).

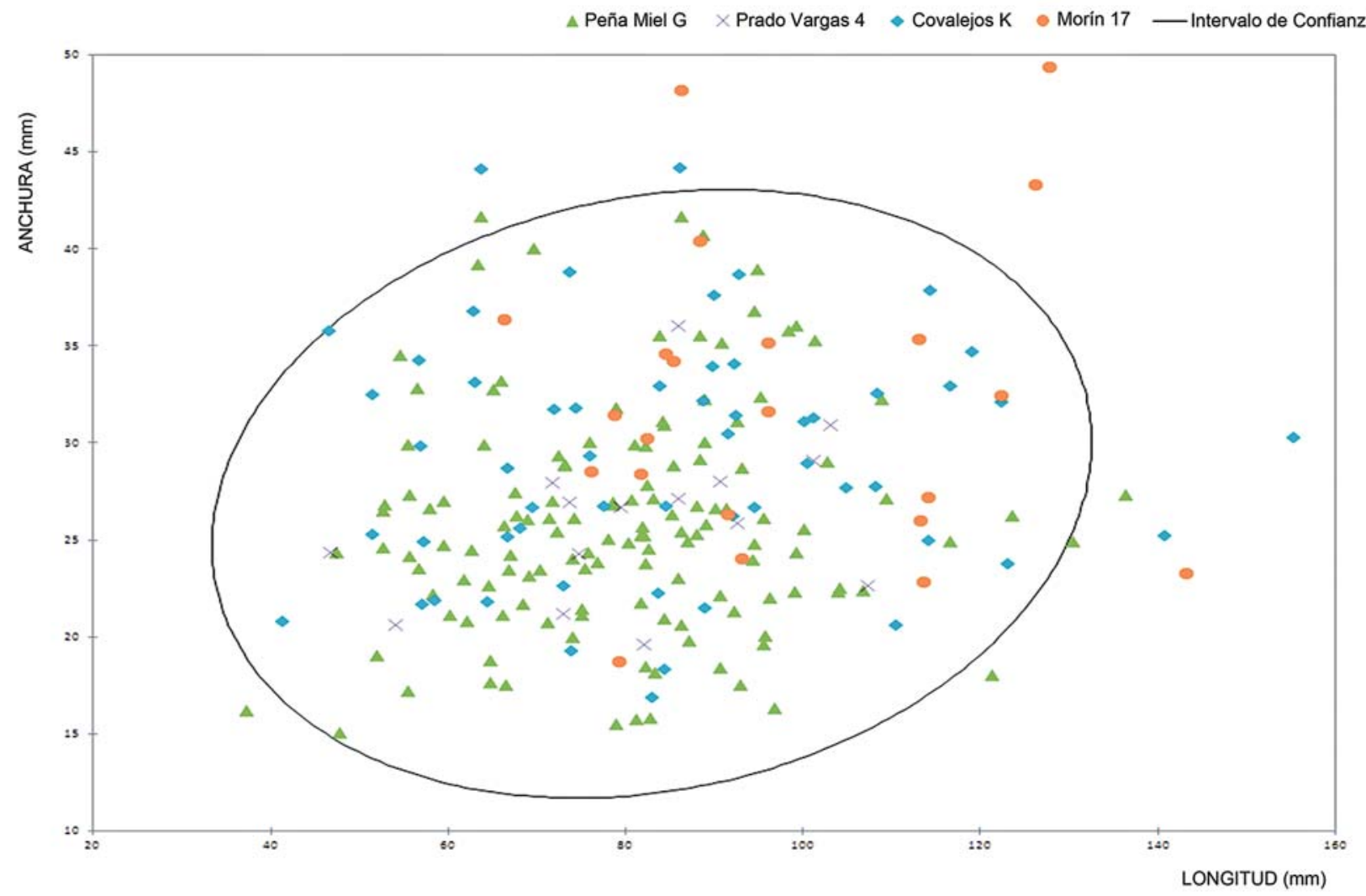

Fig. 4. Longitud y anchura (en $\mathrm{mm}$ ) de los soportes de retocadores estudiados, organizados por los distintos conjuntos / Length and Width (in mm) for the retoucher blanks studied -organized by different assemblages. 


\begin{tabular}{|l|l|l|}
\hline & Longitud & Anchura \\
\hline Peña Miel G & $76,9 \pm 17,3 \mathrm{~mm}$ & $25,9 \pm 5,7 \mathrm{~mm}$ \\
\hline Prado Vargas 4 & $81,2 \pm 16,9 \mathrm{~mm}$ & $26,1 \pm 4,2 \mathrm{~mm}$ \\
\hline Covalejos K & $84,8 \pm 24,1 \mathrm{~mm}$ & $29,2 \pm 6,2 \mathrm{~mm}$ \\
\hline Morín 17 & $98 \pm 20,2 \mathrm{~mm}$ & $32,3 \pm 7,9 \mathrm{~mm}$ \\
\hline
\end{tabular}

Tabla 2: Medias y desviaciones estándar para la Longitud y la Anchura de los soportes completos / Means and standard deviations for Lenght and Width of complete blanks.

En el resto de yacimientos (Peña Miel Nivel G, Prado Vargas Nivel 4 y Nivel Covalejos K), las dimensiones de soportes son muy similares entre sí. Y aunque en estos conjuntos predominan los restos de Cervus elaphus, este hecho de por sí solo no explicaría las características tan similares de las herramientas. En cada conjunto hay diferentes elementos anatómicos (metápodo, tibia, húmero, etc.), y los huesos distintos típicamente producen astillas con diferentes morfologías y tamaños. Y sin embargo, las medias de Longitud y Anchura de los soportes son casi idénticas en las tres muestras. Según nuestro criterio, esto sugiere que hubo una se- lección a la hora de obtener los retocadores. De ser este el caso, los condicionantes de la selección podrían explicarse fácilmente en términos técnicos: los soportes tienen la forma adecuada y una masa óptima para las tareas de retoque.

El gráfico de la figura 5 ilustra la variabilidad de las dimensiones de los soportes (específicamente Longitud, Anchura y Espesor), a partir de una comparación de las desviaciones estándar normalizadas, y sobre la base de sus respectivos valores medios. Esto lógicamente supone que los datos no deben ser leídos como dimensiones o tamaños en términos absolutos, sino como expresiones de la variabilidad. También se proporcionan datos de conjuntos experimentales (MOZOTA, 2012: 49-73; MOZOTA, 2013) como referencia visual y elemento de comparación. Como se ha comentado antes brevemente, la experimentación consideró dos estrategias que representan dos extremos entre todas las estrategias posibles para la obtención de soportes: (1) una producción intencional, con el objetivo de obtener el mayor número posible de soportes con el tamaño adecuado para las tareas de retoque; y (2) la selección "ad hoc" de soportes a partir los conjuntos de esquirlas, una vez fracturado el hueso para la extracción de la grasa medular.

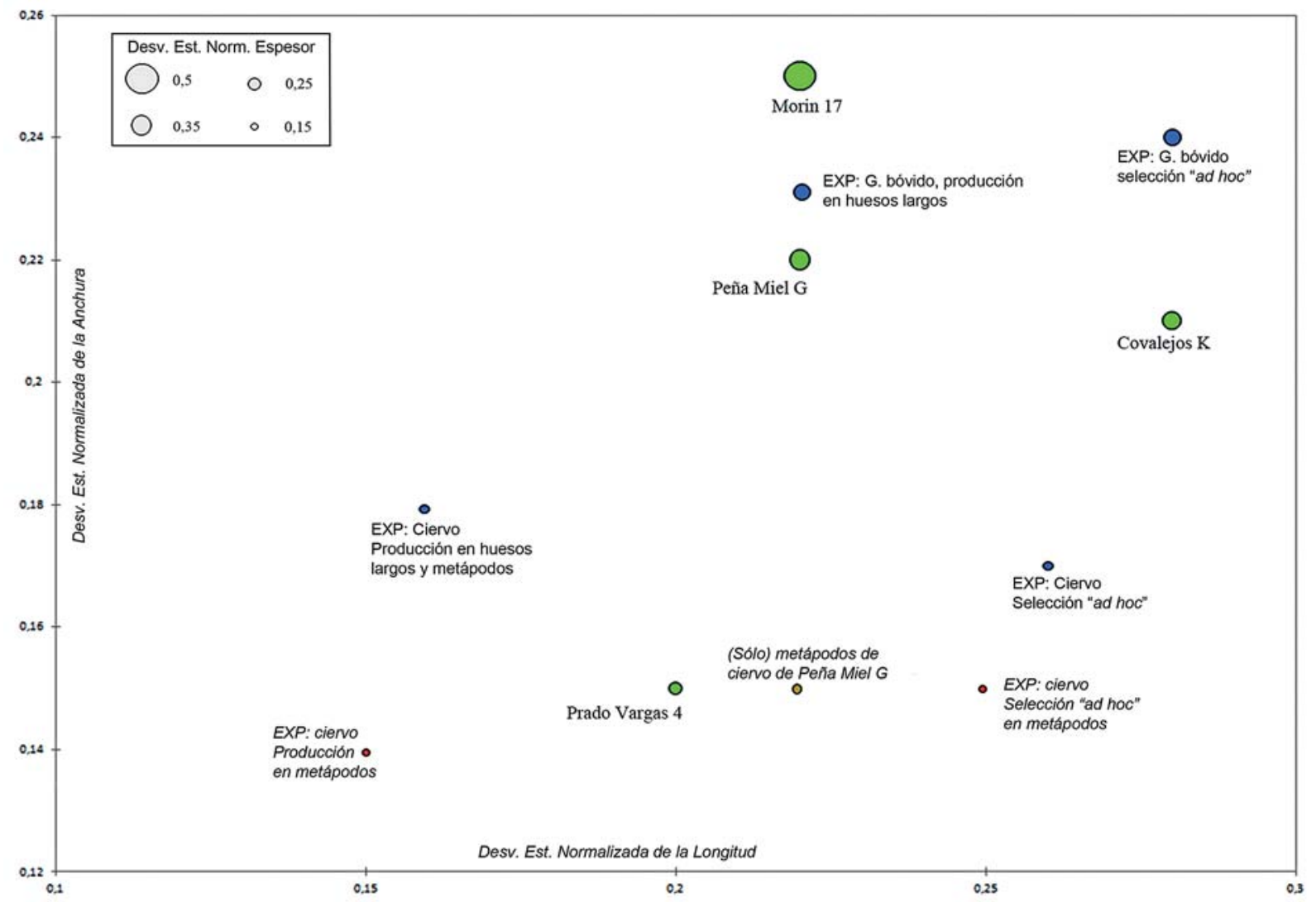

Fig. 5. Gráfico que resume la variabilidad en el tamaño de los soportes, para los diferentes conjuntos estudiados. Se categorizan las desviaciones estándar normalizadas de las dimensiones de los útiles óseos a partir de cada muestra arqueológica (considerando sólo los retocadores no fragmentarios). También se han incluido muestras experimentales para las comparaciones / Graphic summary of the variability in the size of the blanks, for the different sets studied. Normalized standard deviations of bone tools dimensions are categorized by archaeological assemblages (only non-fragmentary tools considered). Experimental samples are provided for comparison. 
Una lectura conjunta de los datos sugiere que la variabilidad en el Espesor y en la Anchura tiene una fuerte relación con el taxón utilizado como materia prima (por ejemplo, gran bóvido vs. Cervus elaphus). Por otro lado, la variabilidad en la Longitud parece independiente de las variables taxonómicas, y probablemente está relacionada con la estrategia de selección de los soportes.

Al centrar el interés en la variable de la Longitud, se hace evidente que la muestra de Covalejos Nivel K destaca del resto, por su mayor variabilidad en dicha dimensión. Esto podría deberse a una selección menos cuidadosa de los soportes. En los otros conjuntos (Morín Nivel 17, Peña Miel Nivel G y Prado Vargas Nivel 4) hay mucha menos variabilidad en la Longitud, lo que podría indicar una selección cuidadosa de las herramientas. Esto es muy probablemente lo que sucede Peña Miel y Prado Vargas, pero debemos tener en cuenta la naturaleza sesgada de la muestra de Morín.

Por otra parte, en Peña Miel Nivel G hay un gran número de soportes que son fragmentos de metápodo, lo que permite una comparación con el subconjunto correspondiente del programa experimental. Los resultados sugieren la existencia de elementos adicionales de selección y/o producción para estos subconjuntos. Además, el estudio cualitativo de los materiales de Peña Miel Nivel G reveló la existencia de un procedimiento de fracturación más cuidado (Figura 6). Dicho proceso se basa en la repetición de impactos bipolares (utilizando martillo y yunque líticos). El golpeo reiterado sigue una línea longitudinal a lo largo del eje mayor del hueso. Este procedimiento es bien conocido, para el Paleolítico, como un sistema típico de fractura para la obtención de la médula ósea (BINFORD, 1978, VINCENT, 1993, VALENSI y PSATHI, 2004). No obstante, en el caso de Peña Miel, el golpeo parece tener como objetivo el obtener fracturas especialmente controladas. Esta conclusión se basa en nuestra observación cualitativa de (1) los puntos de percusión, cuidadosamente seleccionados, (2) la precisión de cada impacto, y (2) su reiteración a lo largo de una línea recta.

En lo que se refiere al origen anatómico y taxonómico de los soportes, cada conjunto muestra sus propias características y matices. Debido a que la información de las publicaciones y registros originales presenta diferentes formatos, y no hay disponible información completa de NISP
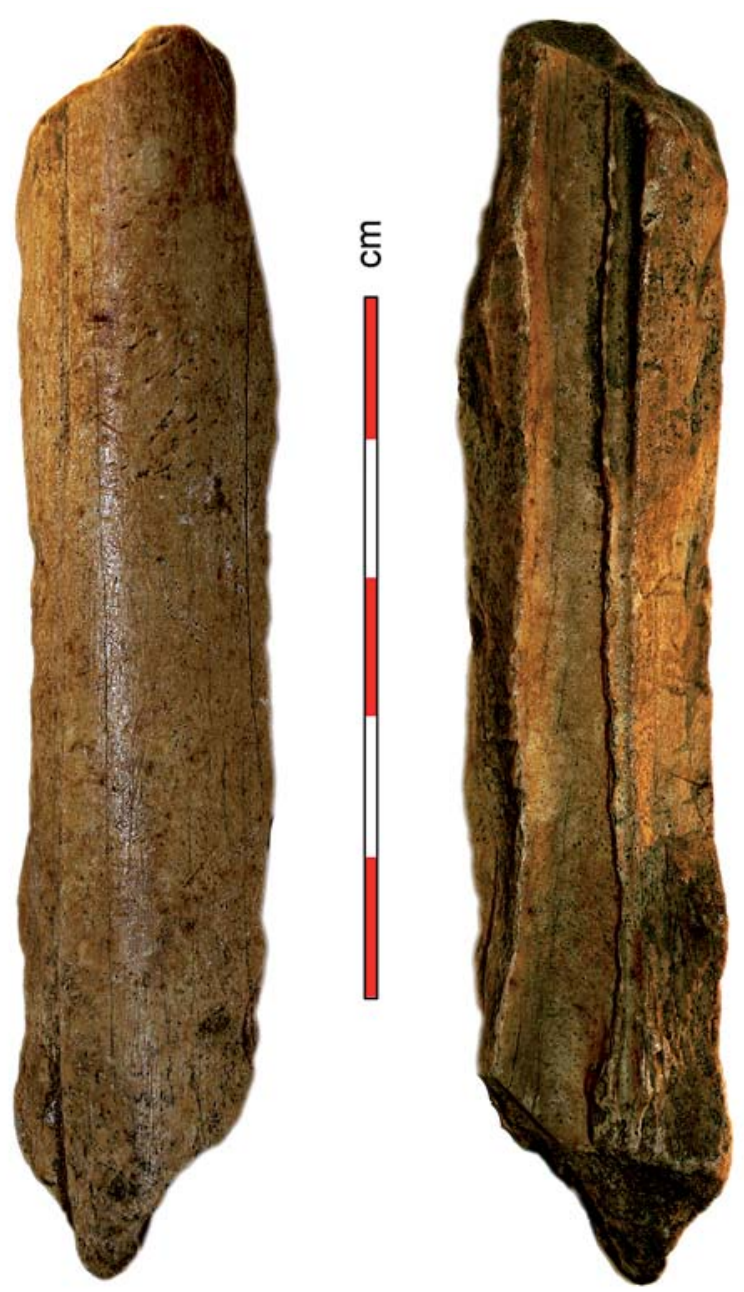

Fig. 6. Retocador óseo en fragmento de metápodo de Cervus elaphus, de Peña Miel Nivel G. Se pueden observar estigmas tecnológicos de percusión bilateral recurrente (e. g. sobre yunque) / Peña Miel Level G bone retoucher on Cervus elaphus metapodial fragment. Technological stigmas of bilateral recurrent percussion (e. g. on anvil) can be observed.

para todos los conjuntos, hemos optado por una tabla de estimaciones y frecuencias relativas para sintetizar la información. El detalle de los datos disponibles se puede hallar en las publicaciones originales de estos yacimientos (ALTUNA, 1978, 1987; CASTAÑOS 2005; NAVAZO et al., 2005).

\begin{tabular}{|c|c|c|c|c|c|c|c|c|}
\hline & \multicolumn{2}{|c|}{ Peña Miel Lv. G } & \multicolumn{2}{|c|}{ Covalejos Lv. K } & \multicolumn{2}{|c|}{ Morín Lv. 17} & \multicolumn{2}{|c|}{ Prado Vargas Lv. 4} \\
\hline & Fauna & Ret. & Fauna & Ret. & Fauna & Ret. & Fauna & Ret. \\
\hline $\begin{array}{l}\text { Presencia de Bos/Bison sp. \& Equus sp. } \\
\text { (herbívoros talla grande) }\end{array}$ & + & ++ & ++ & ++ & ++++ & ++++ & + & + \\
\hline Presencia de Cervus elaphus & ++++ & ++++ & ++++ & ++++ & ++ & ++ & ++ & ++++ \\
\hline $\begin{array}{l}\text { Presencia de macromamíferos de talla } \\
\text { inferior a la del ciervo }\end{array}$ & ++ & + & + & + & + & - & ++++ & - \\
\hline
\end{tabular}

Tabla 3: Presencia/abundancia de taxones - Restos de fauna vs. Soportes de retocadores / Taxon presence/abundance - Faunal remains vs. Retoucher blanks 
En Peña Miel Nivel G, todos los retocadores provienen de los huesos de macromamíferos, en su mayor parte de Cervus elaphus (MOZOTA, 2012). De hecho, los elementos anatómicos que predominan son los metápodos de ciervo, pero también hay fémures, tibias y húmeros. En menor medida, hay huesos de animales más grandes (Equus sp. y Bos / Bison sp.) y algunos de los retocadores corresponden a huesos de macromamíferos más pequeños (Capra sp. y Rupicapra rupicapra).

Comparando estos datos con el espectro faunístico del Nivel G (ALTUNA, 1987), podemos ver que los huesos de los animales medianos y grandes están sobrerrepresentados en los soportes de utillaje, mientras que los restos de animales más pequeños están infrarrepresentados. Esto indica una preferencia por elementos anatómicos de mayor tamaño y robustez.

En el Nivel K de Covalejos todos los soportes provienen de huesos largos (incluyendo metápodos) de las extremidades de macromamíferos, con la excepción de una costilla de Bos/Bison sp. (MOZOTA, 2012). Principalmente, los soportes provienen de Cervus elaphus incluyendo metápodos, húmeros, fémures y tibias. A los huesos de ciervo le siguen en importancia, aunque en mucho menor número, los huesos de los animales de mayor tamaño (Equus sp.). Y se recurre muy poco a animales más pequeños que los ciervos para obtener retocadores. En cuanto a la fauna presente en el nivel (CASTAÑOS, 2005), la proporción de animales sería grosso modo equivalente a la representación taxonómica en el conjunto del utillaje.

En el Nivel 17 de Morín todos los soportes provienen de huesos largos de las extremidades de grandes y medianos herbívoros, con la excepción de una costilla de un macromamífero indeterminado, aunque de talla grande (MOZOTA, 2012). El conjunto más numeroso procede de los animales grandes (Bos/Bison sp. y Equus sp.) al que siguen los soportes en huesos de Cervus elaphus. No hay evidencia de retocadores en restos de animales más pequeños que los ciervos. Si se compara con la muestra de fauna del nivel (ALTUNA, 1978), hay una buena coincidencia en la distribución (de nuevo, grosso modo).

Por último, en el Nivel 4 de Prado Vargas los soportes también provienen de huesos largos de las extremidades de macromamíferos (MOZOTA, 2012). En su mayor parte son huesos de Cervus elaphus: se trata sobre todo de metápodos, pero también hay húmeros, fémures y tibias. Además de los soportes de Cervus elaphus, hay algunos huesos de animales más grandes (Bos/Bison sp y Equus sp.) y algunos ejemplos de herbívoros más pequeños (Capra sp. y Capreolus capreolus). La comparación con la muestra de la fauna presente en el nivel (NAVAZO et al., 2005), indica una clara preferencia por los soportes en hueso de ciervo. Esto apunta por tanto a una búsqueda de los elementos anatómicos de mayor tamaño y robustez.

\subsection{Análisis de huellas de uso}

Con el fin de analizar la función del utillaje realizamos una selección de los retocadores: tomamos aquellos con una superficie cortical bien conservada y zonas de uso completas (áreas activas, con concentraciones de estigmas funcionales). El primer aspecto considerado fue la morfología de la zona de uso, y su posición sobre la superficie del soporte óseo, con especial atención a su lateralización.

\begin{tabular}{|l|c|c|c|c|}
\hline \multirow{2}{*}{ Conjunto/muestra } & \multicolumn{2}{|c|}{$\begin{array}{l}\text { Dimensiones de } \\
\text { la zona de uso }\end{array}$} & \multicolumn{2}{l|}{ Información de Lateralización } \\
\cline { 2 - 5 } & & & $\begin{array}{l}\text { Áreas laterali- } \\
\text { zadas hacia } \\
\text { lado derecho }\end{array}$ & $\begin{array}{c}\text { Lateralización media } \\
\text { (Valores positivos } \\
\text { derecha) }\end{array}$ \\
\hline Peña Miel G (n=134) & $15,9 \mathrm{~mm}$ & $11,1 \mathrm{~mm}$ & $51 \%$ & $0,2 \mathrm{~mm}$ \\
\hline Covalejos K (n=55) & $20,4 \mathrm{~mm}$ & $12,8 \mathrm{~mm}$ & $72 \%$ & $2,4 \mathrm{~mm}$ \\
\hline $\begin{array}{l}\text { Morín 17 (n=20) } \\
\text { Prado Vargas 4 (n=14) }\end{array}$ & $15,1 \mathrm{~mm}$ & $10,1 \mathrm{~mm}$ & $64 \%$ & $0,3 \mathrm{~mm}$ \\
\hline $\begin{array}{l}\text { EXP. Retoque } \\
\text { presión ciervo }\end{array}$ & $12,4 \mathrm{~mm}$ & $10,6 \mathrm{~mm}$ & $44 \%$ & $-0,4 \mathrm{~mm}$ \\
\hline $\begin{array}{l}\text { EXP Retoque percusión } \\
\text { (ciervo-bóvido) }\end{array}$ & $21,8 \mathrm{~mm}$ & $14,1 \mathrm{~mm}$ & $64 \%$ & $1,9 \mathrm{~mm}$ \\
\hline $\begin{array}{l}\text { EXP Retoque } \\
\text { percusión bóvido }\end{array}$ & $23,5 \mathrm{~mm}$ & $17,6 \mathrm{~mm}$ & $58 \%$ & $1,8 \mathrm{~mm}$ \\
\hline $\begin{array}{l}\text { EXP Retoque } \\
\text { percusión ciervo }\end{array}$ & $20,8 \mathrm{~mm}$ & $10,6 \mathrm{~mm}$ & $71 \%$ & $0,6 \mathrm{~mm}$ \\
\hline
\end{tabular}

Tabla 4: Morfología y lateralización de la zona de uso (conjuntos de retocadores de Peña Miel, Morín, Covalejos y Prado Vargas. Para su comparación, se añaden los datos experimentales para las tareas de retoque por presión y por percusión / Use area morphology and lateralization (retoucher assemblages from Peña Miel, Morín, Covalejos and Prado Vargas. Experimental data for pressure and percussion retouching tasks are provided -for comparison).

En los conjuntos arqueológicos, la morfología y lateralización de las zonas de uso indican claramente que se realizaron tareas de percusión con los soportes. La excepción podría ser el caso de Nivel 17 de Morín. En esta muestra, la total ausencia de lateralización es una característica notable. Pero nos inclinamos a considerar que no es una característica técnica relevante, sino un artefacto estadístico. Es necesario recordar que se trata de una pequeña muestra $(n=20)$, y además proviene de una excavación antigua, con recogida selectiva de materiales, y con una compleja historia de conservación museística (YRAVEDRA y GÓMEZ CASTANEDO, 2011; MOZOTA, 2012: 276-278).

Los datos arqueológicos y experimentales también sugieren que las tareas se llevaron a cabo por sujetos predominantemente diestros en todos los conjuntos. Esta inferencia puede ser considerada especialmente robusta para los conjuntos con un gran número de retocadores: Covalejos Nivel K ( $n=55)$ y Peña Miel Nivel G $(n=134)$. 
El análisis de las huellas de uso también produjo resultados significativos. La primera observación notable es que, con una excepción, todos los retocadores fueron puestos en uso mientras que el hueso todavía estaba fresco o semi-fresco. Sólo hay un caso de uso (reutilización, como se explica más adelante) con el hueso completamente seco. Por otra parte, en todos los casos analizados se hallaron los estigmas típicos de las tareas de retoque de percusión, y por tanto no hay rastros de retoque por presión.

En cuanto a la determinación del tipo específico de retoque, el gráfico (Figura 7) sugiere que la mayoría de los conjuntos muestran características intermedias entre el retoque de tipo "Quina" (directo, escamoso-escaleriforme sobre lascas espesas) y "Simple" (directo, no invasivo, sobre lascas delgadas), tal y como fueron considerados en la experimentación (MOZOTA, 2012: 74-95; MOZOTA, 2013). Como elemento de comparación, añadimos datos concretos de dos estratos arqueológicos del yacimiento musteriense de Axlor (Dima, Bizkaia), los niveles B y D. En estos depósitos se hallaron importantes conjuntos de útiles con retoque tipo "Quina" (RíOS GARAIZAR, 2008). Estos datos adicionales validan la robustez de las inferencias realizadas a partir de los estigmas de uso. Por otro lado, la posición relativa en el gráfico del Nivel 4 de Prado
Vargas (ligeramente desplazada de las otras, y más cerca del retoque por presión) podría deberse al tipo de retoque, pero es más probable que se trate de un artefacto estadístico (relacionado con el pequeño número de elementos analizados, $n=14$ ). Si que podemos afirmar, en todo caso, que la morfología de los estigmas y la forma y posición de las zonas de uso no sugieren la presencia de las tareas por presión, dentro del conjunto de Prado Vargas.

En la dicotomía de retoque "Simple" vs. "Quina", los datos sugieren que las muestras más representativas (Peña Miel Nivel G y Covalejos Nivel K) tienen características típicas de ambas tareas, con más peso de retoque "Quina" en Covalejos y del retoque "Simple" en Peña Miel. Los estudios del utillaje lítico del Nivel G de Peña Miel (UTRILLA y MONTES, 1987: 58) proponen una importancia de retoque "Quina", con mayor incidencia en las herramientas de sílex. Esto puede parecer contrario a la posición del conjunto en el gráfico comparativo, pero debemos considerar que también se documentaron en este nivel otros materiales (p. e. cuarcita) y otros tipos de retoque. Para el nivel K de Covalejos los datos arqueológicos disponibles, sobre la lítica, son muy escasos. Se citan industrias musterienses, incluida la técnica de talla "Quina", pero no hay ninguna referencia a retoque "Quina" (SANGUINO y MONTES BARQUÍN, 2005: 501).

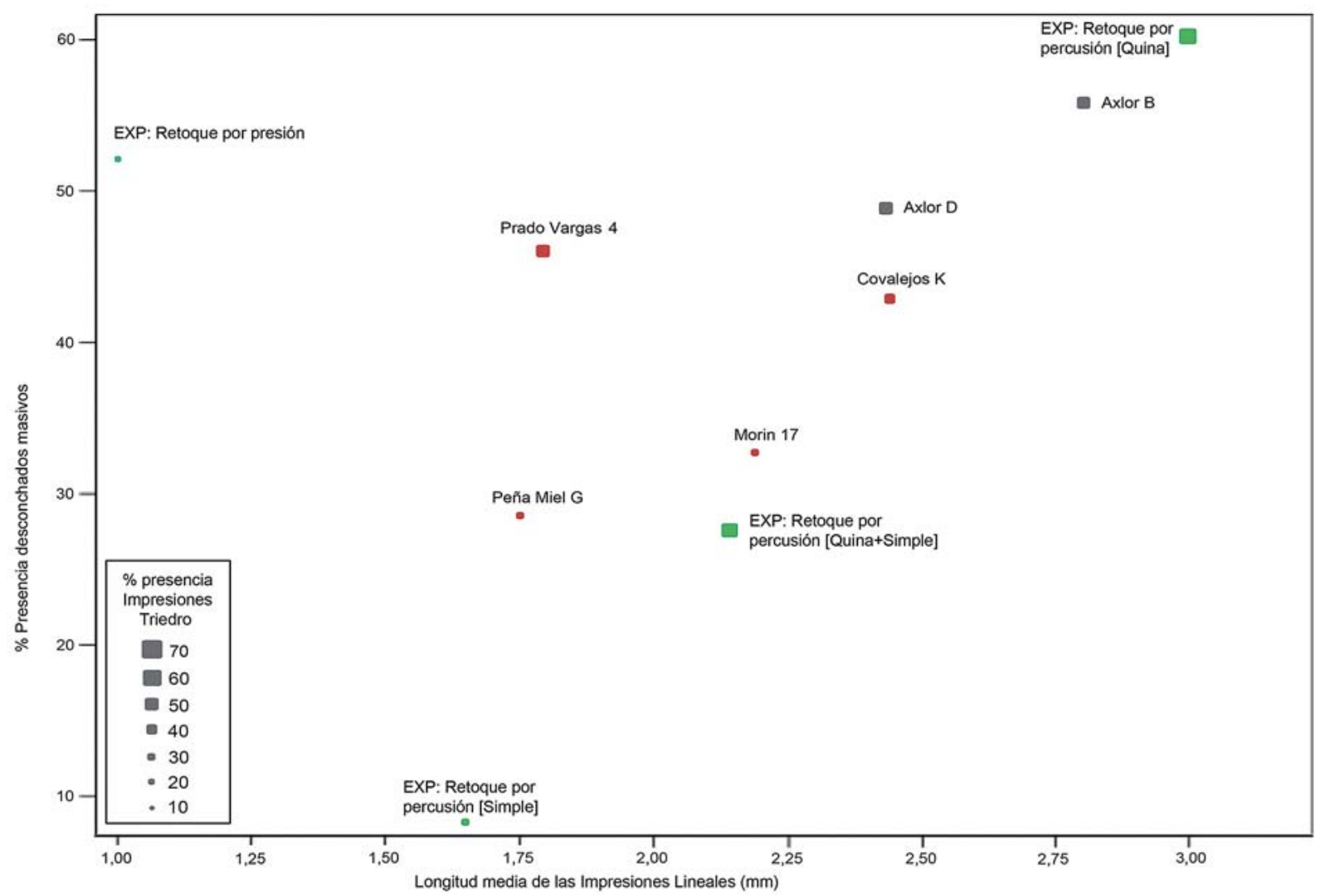

Fig. 7. Huellas de uso en los diferentes conjuntos de retocadores (y muestras experimentales). El gráfico muestra los rasgos más diagnósticos para inferir las tareas de retoque. Se aportan datos experimentales y del sitio de Axlor (Dima, Bizkaia) para su comparación / Traces of use in different assemblage of retouchers (and experimental samples). The graphic plots the most diagnostic features to infer the retouching tasks. Experimental data and data from Axlor site (Dima, Bizkaia -North of Iberia) are provided for comparison. 
UN ANÁLISIS TECNO-FUNCIONAL DE LOS RETOCADORES ÓSEOS MUSTERIENSES DEL NORTE DE LA PENÍNSULA IBÉRICA,

\begin{tabular}{|c|c|c|c|c|}
\hline \multicolumn{5}{|c|}{ Datos arqueológicos } \\
\hline Conjunto & $\begin{array}{l}N^{o} \text { medio de Impresiones } \\
\text { Lineales por zona de uso }\end{array}$ & $\begin{array}{l}\text { Índice de útiles con } \\
2+\text { zonas de uso }\end{array}$ & $\begin{array}{l}\text { Índice de zonas de uso } \\
\text { con reacondicionamiento }\end{array}$ & Evidencia de reciclado \\
\hline Peña Miel G & 29 & 0.26 & 0.03 & No \\
\hline Covalejos $\mathrm{K}$ & 43 & 0.16 & 0.15 & No \\
\hline Morín 17 & 33 & 0.12 & 0.0 & No \\
\hline \multirow[t]{2}{*}{ P. Vargas 4} & 43 & 0.06 & 0.06 & Si (1 caso) \\
\hline & & Datos experimentales & & \\
\hline Muestra & $\begin{array}{l}N^{\circ} \text { medio de Impresiones } \\
\text { Lineales por zona de uso }\end{array}$ & $\begin{array}{l}\text { Equivalencia en } \\
\text { tiempo de trabajo }\end{array}$ & $\begin{array}{l}\text { Número real de } \\
\text { percusiones }\end{array}$ & $\begin{array}{l}\text { Estado del útil } \\
\text { tras el uso }\end{array}$ \\
\hline $\begin{array}{l}\text { Percusión, retoque } \\
\text { "Poco intenso" }\end{array}$ & 30,6 & 1-2 minutos & 40 a 80 & Eficiencia total \\
\hline $\begin{array}{l}\text { Percusión, retoque } \\
\text { "Intensidad media" }\end{array}$ & 41,6 & 3-4 minutos & 160 a 180 & $\begin{array}{l}\text { Eficiencia ligeramente } \\
\text { reducida }\end{array}$ \\
\hline $\begin{array}{l}\text { Percusión, retoque } \\
\text { "Muy intenso" }\end{array}$ & 59,1 & 5-8 minutos & 200 a 250 & $\begin{array}{l}\text { Eficiencia fuertemente } \\
\text { reducida }\end{array}$ \\
\hline
\end{tabular}

Tabla 5: Intensidad de uso y evidencias de reacondicionamientos y reciclado / Intensity of use/refitting and recycling evidence.

Los datos también ponen de manifiesto diferentes estrategias para gestionar el mantenimiento de los útiles. Cuando se compara con el marco experimental, la intensidad de las tareas de retoque en los conjuntos arqueológicos es de baja a media. La proporción de "retocadores múltiples" (con varias zonas de uso) es muy variable entre los conjuntos. Asimismo, el índice de presencia de zonas de uso reacondicionadas también varía entre las distintas series.

Como se dijo antes, Peña Miel Nivel G y Covalejos Nivel K son los conjuntos más grandes y estadísticamente más fiables. En esos casos, las estrategias para la gestión y mantenimiento de las herramientas son muy diferentes. El número de impresiones por área de uso es más importante en Covalejos Nivel K, y también la evidencia de mantenimiento de los útiles por reacondicionamiento de la zona activa. Peña Miel Nivel G muestra un menor número de impresiones por área de uso, y menor presencia de reacondicionamientos. Pero, por otra parte, ese mismo conjunto tiene una proporción más importante de retocadores con varias zonas de uso.

Estos datos nos muestran dos formas alternativas de gestionar las herramientas: Ios útiles de Covalejos Nivel K se utilizan intensamente (hasta comprometer su eficiencia), y son reacondicionados por raspado. Y por otra parte, los útiles de Peña Miel Nivel G tienden a presentar varias zonas activas, en partes distintas del soporte, que se utilizan con menor intensidad, lo que requiere menos tareas de reacondicionamiento.

Además, se ha documentado el reciclaje de un retocador de Prado Vargas: después de una utilización y probable abandono, este útil se recuperó en un momento posterior

El primer uso del útil se produjo cuando el hueso aún estaba fresco; a continuación, el hueso se secó en un intervalo de tiempo indeterminado, y más tarde se volvió a utilizar (figura 8).

\section{4.- BALANCE Y DISCUSIÓN}

Como balance de los datos aquí expuestos, en primer lugar señalaremos que nuestro análisis tafonómico permitió determinar que todos los conjuntos de utillaje provienen de restos óseos de animales procesados por agentes antrópicos. Los restos de fauna seleccionados como soportes sufrieron un acceso muy limitado, y secundario, por parte de otros carnívoros.

El estudio de la captación de los soportes nos permite inferir una preferencia por los huesos resistentes y largos, en particular los que provienen de las extremidades de animales grandes y medianos: básicamente de los géneros Cervus, Bos/Bison y Equus. Esta selección de esquirlas diafisarias, robustas y alargadas, se ha detectado en otros contextos del Paleolítico Medio y Superior, como es el caso de Fumane en Italia (JÉQUIER et al., 2012). De forma muy ocasional, se utilizaron también costillas (de esos mismos animales) o bien huesos largos de herbívoros de tamaño pequeño. Es importante señalar que, aunque la materia prima disponible cambia en cada yacimiento (o al menos, cambia la proporción de taxones documentados), la selección de los soportes sigue centrándose en los mismos elementos y especies. Esto permite deducir que los agentes antrópicos hacen caso omiso de los restos menos adecuados para obtener retocadores.

Al abordar la morfometría de los útiles óseos, se ha hecho evidente la existencia de varios criterios importantes a la hora de seleccionar los soportes, que son el tamaño, la forma y la masa de los mismos. Esto se puede vincular a la búsqueda de una eficiencia, o cuando menos una efectividad, en las tareas que se realizan con los retocadores.

La variabilidad en el formato del soporte es generalmente baja. Pudo -o no- darse una producción intencional de los soportes, pero en cualquier caso los datos sí que evidencian una fuerte selección. Esta se produce entre las esquirlas de fauna disponibles, y está en función de las cualidades técnicas de los soportes. Nuestros resultados 


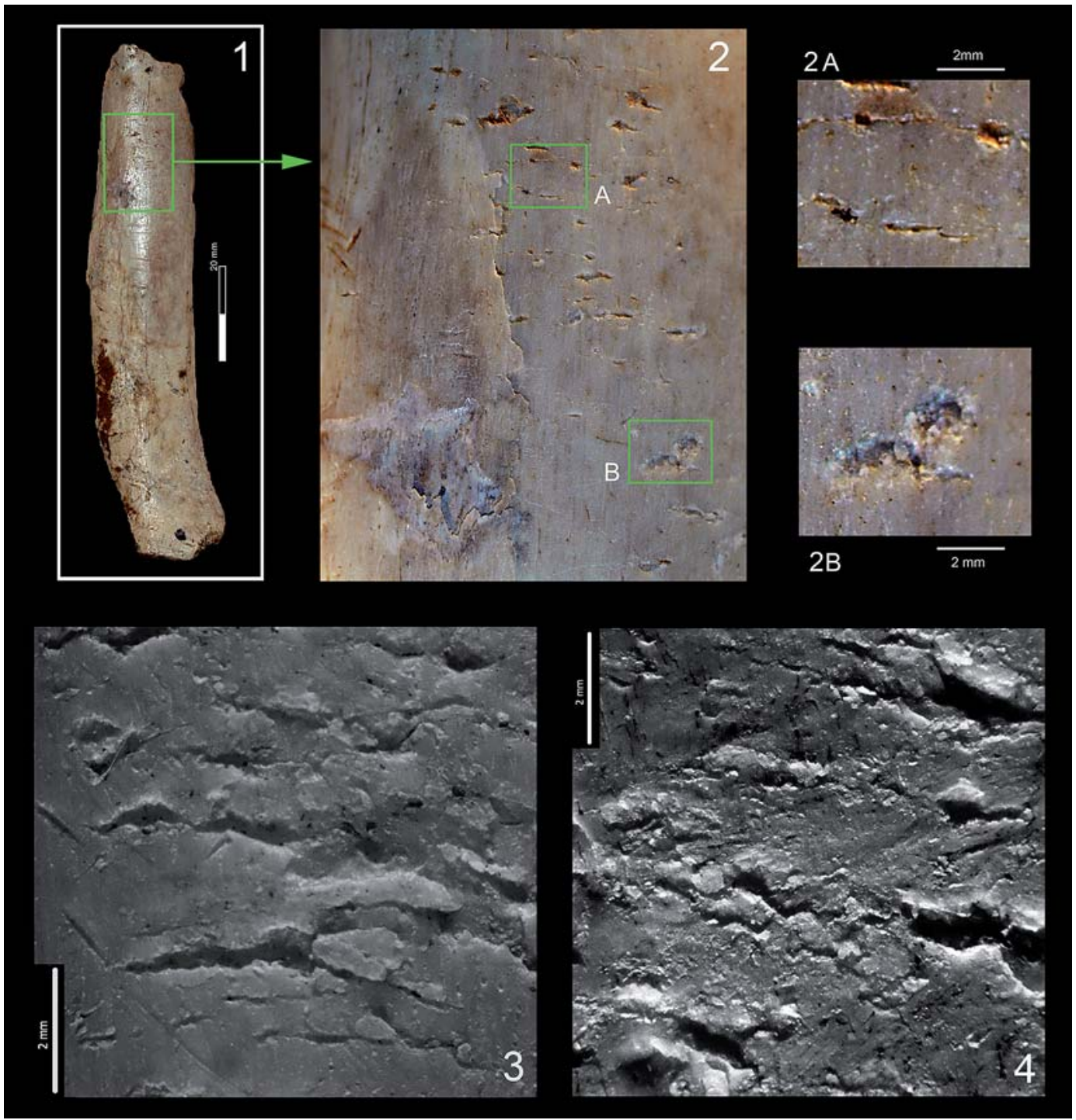

Fig. 8. Retocador óseo de Prado Vargas Nivel 4, con huellas de uso producidas con el hueso fresco, y una vez seco. 1: Vista general de la cara cortical. 2. Detalle de la zona de uso. 2A: Detalle de impresiones sobre hueso fresco. 2B: Detalle de impresiones sobre hueso seco. 3: Impresiones experimentales sobre el hueso fresco. 4. Impresiones experimentales sobre el hueso seco / Vargas Prado Level 4 bone retoucher with traces of use in both fresh and dry bone. 1: General view of the cortical side. 2: Detail of the use area. 2A: Detail of impressions on fresh bone. 2B: Detail of impressions on dry bone. 3: Experimental impressions on fresh bone. 4. Experimental impressions on dry bone.

también son similares a los obtenidos recientemente (JÉQUIER et al., 2012) para los conjuntos del Musteriense y Uluzziense de Fumane (Italia).

Además, el grado de variabilidad morfométrica es diferente en cada conjunto, lo que sugiere diferentes grados de selección de los soportes. Y en el caso del Nivel G de Peña Miel, el análisis cualitativo de los estigmas de fractura ósea sugiere una posible producción intencional de algunos soportes. En concreto, los que fueron obtenidos a partir de metápodos de Cervus elaphus. Por otra parte, esta producción no sería incompatible con las tareas de obtención de la médula ósea.

En cuanto al uso de los retocadores, en casi todos los casos se produjo mientras los huesos todavía estaban frescos o semi-frescos, lo que implica el reconocimiento de las cualidades (elasticidad y resistencia) del material en ese estado. Además, esto significa que se utilizaron en un momento cercano a la muerte del animal, y en el ámbito de la gestión y consumo de dicho recurso.

Las tareas de retoque son realizadas por percusión, y no hay evidencias de retoque por presión en estos conjuntos, lo que sirve como confirmación provisional de dicha ausencia en contextos del Paleolítico Medio. Las huellas de uso propiamente dichas muestran cierta variabilidad y yuxtaposición en sus tipos, lo que significa que probablemente se combinaron diversos tipos de retoque en todos los conjuntos. En general, encontramos la combinación de las características de los tipos de retoque "Quina" y "Simple" (al menos, tal y como fueron conceptualizados y ejecutados en el programa experimental). La presencia 
proporcional de cada uno de estos tipos también varía entre los conjuntos, probablemente en respuesta a las necesidades específicas de la gestión lítica.

También se han documentado diferencias relevantes en la forma de gestionar los retocadores. En concreto, las estrategias de mantenimiento varían entre los distintos conjuntos. En algunos casos se efectúan mediante reacondicionamientos, y en otros se recurre al uso de múltiples zonas activas. Además, hemos podido documentar un caso de un retocador reciclado, en el sentido de que fue abandonado, y retomado su uso un tiempo después. Este es, en nuestra valoración, un caso muy específico, único, y no se deberían sacar conclusiones generales al respecto.

A un nivel más amplio, esta serie de análisis nos permite hacer inferencias significativas sobre los grupos neandertales que generaron el registro arqueológico. En primer lugar, resulta evidente la importancia de estas herramientas para la gestión de otros instrumentos de producción (las herramientas líticas), y queda atestiguada por su presencia y abundancia en los yacimientos estudiados y en muchos otros contextos del Paleolítico Medio de Eurasia.

Es posible citar muchos trabajos (SEMENOV, 1964; RIGAUD, 1977; VINCENT, 1993; PATOU-MATHIS, 2002; MOZOTA, 2009) que ya atestiguaron la relación entre retocadores y herramientas líticas, por lo que no insistiremos en este punto. Por otro lado, cabe señalar que la gestión del utillaje lítico por retoque de tipo "Quina" se ha relacionado (en los términos más generales) con un tratamiento intensivo de diferentes materiales (CARRIÓN et al., 2008) y/o con actividades grupales con un componente logístico (RíOS GARAIZAR, 2008). El retoque "Simple" puede corresponder a una amplia gama de tareas, aunque hay una tendencia a interpretarlo como un marcador del trabajo doméstico y mantenimiento ad hoc del utillaje (ROLLAND Y DIBBLE, 1990; RÍOS GARAIZAR, 2008).

En este trabajo también hemos demostrado cómo la obtención y uso de retocadores óseos tienen una relación sincrónica (o cuasi-síncrona) con el tratamiento de los restos de fauna. Casi todos los soportes se utilizaron con el hueso en estado fresco, antes de que perdiera sus cualidades óptimas para el retoque. Además, los datos muestran que los soportes fueron cuidadosamente seleccionados a partir de los restos de fauna disponibles, buscando un formato determinado. Y para el caso de Peña Miel Nivel G, se documenta una posible producción de retocadores en metápodos de Cervus elaphus.

Las características del utillaje óseo en su conjunto coinciden razonablemente con una producción colectiva con algún componente logístico, que además estaría condicionado por la necesidad de aplicar una cierta intensidad en los trabajos de retoque.

Una vez hecho balance de los aspectos comunes a los diferentes conjuntos, es necesario referirse a los elementos de variabilidad individual. La primera cuestión relevante es la variedad detectada en el tipo de tareas realizadas con cada conjunto de retocadores, como se infiere del estudio de las huellas de uso. Esa variabilidad puede representar formas concretas de poner en práctica lo que parece ser una estrategia estructural, común a los diferentes conjuntos. Y vendría dada por las necesidades concretas de retoque lítico de cada sitio.

Sin embargo, hay otro elemento de variabilidad que no parece relacionado con las necesidades de la gestión lítica (es decir, las tareas de retoque). Es el caso de los modos de gestión de los propios retocadores óseos. Y, en particular, los mecanismos que prolongan la vida útil de las herramientas, y mantienen su funcionalidad en un estado óptimo.

A partir de los dos conjuntos que son estadísticamente más fiables (Peña Miel Nivel G y Covalejos Nivel K) se documentan dos estrategias para la gestión de la vida del útil. Y aunque ambas son someras y sencillas, también son conceptualmente muy diferentes. Estas estrategias no pueden explicarse fácilmente por las diferencias en las materias primas disponibles, o en los mecanismos de selección, o en el uso de los retocadores. Y esto sugiere que pueden reflejar diferentes prácticas de los grupos, o tradiciones técnicas culturales.

\section{5.- CONCLUSIONES}

Nuestro estudio ha demostrado cómo los retocadores de hueso se integran con diversas áreas productivas de la economía de los grupos neandertales, siendo elementos clave que sirven de puente entre las diferentes áreas de subsistencia. En particular, los retocadores se sitúan entre dos áreas clave: la recogida y gestión de los recursos animales, y la gestión de los recursos minerales (herramientas líticas). Por lo tanto, un retocador no puede considerarse un útil de "fortuna" o "ad hoc"(CHASE, 1990). Las estrategias para obtener y gestionar estas valiosas herramientas no se improvisan o dejan al azar. Al contrario, responden a una serie de criterios que son comunes a los diferentes conjuntos estudiados. Dichas características comunes sugieren una similitud estructural entre los grupos, a la hora de configurar la gestión de sus herramientas. Pero, al mismo tiempo, hallamos al menos dos ámbitos de variabilidad: (1) una flexibilidad en las tareas realizadas, que probablemente se relaciona con las demandas específicas del retoque lítico para ese caso; y (2) una cierta diversidad en la forma de mantener y reacondicionar los útiles óseos, que puede estar relacionada con las prácticas culturales o tradiciones de los grupos.

\section{6.- AGRADECIMIENTOS}

Queremos agradecer a todas las personas que nos han ayudado en el proceso de estudio de los materiales aquí presentados, y que nos han permitido ofrecer este trabajo gracias a sus valiosos consejos, críticas, revisiones, y en otros casos por su ayuda y buenas gestiones para acceder a los propios materiales arqueológicos. En particular a Carlos Diez-Fernández Lomana, Marta Navazo, Ramón Montes Barquín, Jesús González Urquijo, Juan José Ibáñez, Xavier Terradas, Javier Baena, Rafael Bolado del Castillo y Joseba Ríos Garaizar. 


\section{BIBLIOGRAFÍA}

ABRAMS, G., BELLO, S. M., DI MODICA, K., PIRSON, S. \& BONJEAN, D.

2014 When Neanderthals used cave bear (Ursus spelaeus) remains: Bone retouchers from unit 5 of Scladina Cave (Belgium). Quaternary International 326-327, 274-287. doi:10.1016/j.quaint.2013.10.022

ALCÁNTARA, V., BARBA, R., BARRAL, J. M., CRESPO, A. B., EIRIZ, A. I., FALQUINA, A., HERRERO, S., IBARRA, A., MEGÍAS, M., PÉREZ GIL, M., PÉREZ TELLO, V., ROLLAND, J., YRAVEDRA, J., VIDAL, A. \& DOMIINGUEZ-RODRIGO, M.

2006 Determinación de procesos de fractura sobre huesos frescos: Un sistema de análisis de los ángulos de los planos de fracturación como discriminador de agentes bióticos. Trabajos de prehistoria 63/1, 37-45. doi:10.3989/tp.2006.v63.i1.3

\section{ALTUNA, J.}

1978 Los mamíferos de Cueva Morín, en GONZÁLEZ ECHEGARAY, J. \& FREEMAN, L. G. Vida y muerte en Cueva Morín. 201-209. Institución Cultural de Cantabria. Santander.

1987 La fauna de macromamíferos, en UTRILLA, P. et al. La cueva de Peña Miel. Nieva de Cameros, La Rioja. Excavaciones Arqueológicas en España 154.103-108. Ministerio de Cultura. Madrid.

\section{ARMAND, D. \& DELAGNES, A}

1998 Les retouchoirs en os d'Artenac (couche 6c): perspectives archéozoologiques taphonomiques et expérimentales, en BRUGAL, J. P., MEIGNEN, L. \& PATHOU-MATHIS, M. XVIII Rencontres internacionales d'archéologie et d'histoire d'Antibes. 1997; Économie préhistorique: les comportements de subsistance au Paléolithique. 205214. APDCA. Sophia Antipolis.

\section{BARANDIARÁN, I.}

1987 Manipulación y uso de restos óseos, en UTRILLA, P. et al. La cueva de Peña Miel. Nieva de Cameros, La Rioja. Excavaciones Arqueológicas en España 154. 87-101. Ministerio de Cultura. Madrid.

\section{BINFORD, L. R.}

1978 Nunamiut ethnoarchaeology. Academic Press. New York.

\section{BLUMENSCHINE, R. J., MAREAN, C. W. \& CAPALDO S. D.}

1996 Blind Tests of Inter-analyst correspondence and Accuracy in the Identification of Cut Marks, Percussion Marks, and Carnivore Tooth Marks on Bone Surfaces. Journal of Archaeological Science 23/4, 493-507. doi: 10.1006/jasc. 1996.0047

CARRIÓN, E., BAENA, J., CONDE-RUIZ, C., CUARTERO, F. \& ROCA M.

2008 Variabilidad tecnológica en el Musteriense de Cantabria. Treballs d'Arqueologia 14, 279-318.

\section{CASTAÑOS, $P$}

2005 Revisión actualizada de las faunas de macromamiferos del Würm antiguo en la Región Cantábrica, en MONTES, R. \& LASHERAS, J. A. Neandertales Cantábricos. Estado de la cuestión, Monografías 20. 201-207. Museo de Altamira. Madrid.
CHASE, P. G

1990 Tool-making tools and Middle Paleolithic behavior. Current Anthropology 31, 443-447. http://www.jstor.org/ stable/2743276.

DAUJEARD , C., MONCEL, M.-H., FIORE, I., TAGLIACOZZO, A., BINDON, P. \& RAYNAL, J.-P

2014 Middle Paleolithic bone retouchers in Southeastern France: Variability and functionality. Quaternary International326-327, 492-518. doi:10.1016/i.quaint.2013.12.022

\section{D'ERRICO, F. \& VILLA, P.}

1997 Holes and grooves: the contribution of microscopy and taphonomy to the problem of art origins. Journal of Human Evolution 33/1, 1-31. DOI: 10.1006/jhev.1997.0141.

FREEMAN, L. G.

1971 Los niveles de ocupación musteriense, en GONZÁLEZ ECHEGARAY, J. \& FREEMAN, L. G. Cueva Morín. Excavaciones. 1966-1968. 27-134. Patronato de las Cuevas Prehistóricas de la Provincia de Santander. Santander.

\section{GAUDZINSKI, S}

1999 Middle Palaeolithic Bone Tools from the Open-Air Site Salzgitter-Lebenstedt (Germany). Journal of Archaeological Science 26/4, 125-141. DOI: 10.1006/jasc.1998.0311

HENRI-MARTIN, L.

1906 Maillets ou enclumes en os provenant de la couche moustérienne de la Quina (Charente). Bulletin de la Société Préhistorique Française 3, 155-162.

\section{JÉQUIER, C. A., ROMANDINI, M., \& PERESANI, M.}

2012 Les retouchoirs en matières dures animales: une comparaison entre Moustérien final et Uluzzien. Comptes Rendus Palevol 11(4), 283-292. DOI:10.1016/j.crpv. 2011.12.001

LARTET, L.

1866 Potieres primitives instruments en os et silex taillés des cavernes de la vieille Castille (Espagne). Revue Archaeologique 7/XIII, 1-24

LYMAN, R. L.

1994 Vertebrate Taphonomy. Cambridge University Press. Cambridge.

MAROTO, J., VAQUERO, M., ARRIZABALAGA, Á., BAENA, J., BAQUEDANO, E., JORDÁ, J., JULIÀ BRUGUÉS, R., MONTES, R., VAN DER PLICHT, J., RASINES, P. \& WOOD, R.

2012 Middle Palaeolithic chronology: New assessments from Northern Iberia. Quaternary International 247, 15- 25. DOI:10.1016/j.quaint.2011.07.007.

\section{MONTES, L., UTRILLA, P. \& HEDGES, R.}

2001 Le passage Paléolithique Moyen-Paléolithique Supérieur dans la Vallée de l'Ebre (Espagne). Datations radiométriques des grottes de Peña Miel et Gabasa, en ZILHAO, J., AUBRY, T. \& CARVALHO, A. F. Les premiers hommes modernes de la Péninsule Ibérique. Trabalhos de Arqueologia 17. 87-102. Igespar. Lisboa. 
MOZOTA, M.

2009 El utillaje óseo Musteriense del nivel "D" de Axlor (Dima Vizcaya): análisis de la cadena operativa. Trabajos de Prehistoria 66/1, 28-46. DOI: 10.3989/tp.2009.09011.

2012 An experimental programme for the collection and use of retouching tools Made on diaphyseal bone splinters. EXARC journal-Experimental Archaeology 2013/ 2. [On line].http://journal.exarc.net/issue-2013-2/ea/experimental programme-collection-and-use-retouching-tools-madediaphyseal-bone-splinters (fecha de acceso 01/12/2014).

2013 El hueso como materia prima: El utillaje óseo del final del Musteriense en el sector central del norte de la Península Ibérica. Tesis Doctoral. Universidad de Cantabria. Santander. https://www.educacion.gob.es/teseo/mostrarRef. do?ref=995832 (fecha de acceso 15/01/2015).

NAVAZO, M

2010 Hacia el comportamiento humano moderno. Nuevas aportaciones al Paleolítico medio final en el valle del río Arlanza (Hortigüela, Burgos, España). Arqueología Iberoamericana 8, 3-19.

NAVAZO, M., DÍEZ-FERNÁNDEZ LOMANA, C., TORRES, T., COLINA, A. \& ORTIZ, J. E.

2005 La cueva de Prado Vargas. Un yacimiento del Paleolítico Medio en el sur de la cordillera cantábrica, en MONTES, R. \& LASHERAS, J. A. Neandertales Cantábricos. Estado de la cuestión. Monografías 20. 142-166. Museo de Altamira. Madrid.

\section{OUTRAM, A}

2001 A new approach to identifying bone marrow and grease exploitation: Why the 'Indeterminate'. Fragments should not be ignored. Journal of Archaeological Science 28/4 401-410. DOI:10.1006/jasc.2000.0619.

2002 Bone fracture and within-bone nutrients: An experimentally based method for investigating levels of marrow extraction, en MIRACLE P., \& MILNER, N. Consuming Passions and Patterns of Consumption. 51-64. University of Cambridge. Cambridge.

PATOU-MATHIS M.

1999 Les outils osseux du Paléolithique inférieur et moyen en Europe. Problèmes, méthodes et résultats préliminaires, en CAMPS-FABRER, J. \& JULIEN, M. Préhistoire d'os, Recueil d'études sur l'industrie osseuse préhistorique offert à Henriette Camps-Fabrer. 49-57. Publications de I'Université de Provence. Aix-en-Provence.

2002 Compresseurs, percuteurs, retouchoirs ... Os à impressions et éraillures, Industrie de l'os préhistorique, cahier $X$. Editions de la Société Préhistorique Française. Paris.

\section{RIGAUD, A.}

1977 Analyse typologique et technologique des grattoirs magdaléniens de La Garenne à Saint-Marcel (Indre). Gallia préhistoire 20/1, 1-43.

2007 Retouchoirs sur éclats diaphysaires ou «affûtoirs» de Labastide (Hautes-Pyrénées): Du barbarisme scientifique à la rigueur artisanale au travers de l'expérimentation. Archéologie des Pyrénées occidentales et des Landes 26, 193-200.

\section{RÍOS GARAIZAR, J}

2008 Variabilidad tecnológica en el Paleolítico Medio de los Pirineos Occidentales: una expresión de las dinámicas históricas de las sociedades neandertales. Treballs de Arqueologia 14, 171-194.
ROLLAND, N. \& DIBBLE, H. L.

1990 A New Synthesis of Middle Paleolithic Variability. American Antiquity 55, 480-499. http://www.jstor.org/stable/281279.

ROSELL, J., BLASCO, R., FERNÁNDEZ PERIS, J., CARBONELL, E., BARKAI, R., \& AVI, G

2014 Recycling bones in the Middle Pleistocene: Some reflections from Gran Dolina TD10-1 (Spain), Bolomor Cave (Spain) and Qesem Cave (Israel). Quaternary International. En prensa. En línea desde 10/09/2014. doi:10.1016/j.quaint.2014.08.009

SANGUINO, J. \& MONTES BARQUÍN, R.

2005 Nuevos datos para el conocimiento del Paleolítico Medio en el centro de la Región Cantábrica: La Cueva de Covalejos, en MONTES, R. \& LASHERAS, J. A. Neandertales Cantábricos. Estado de la cuestión, Monografías 20. 489-538. Museo de Altamira. Madrid.

\section{SEMENOV, S. A.}

1964 Prehistoric technology; an experimental study of the oldest tools and artifacts from traces of manufacture and wear. Cory, Adams \& Mackay. Londres.

SORESSI, M., MCPHERRON, S. P., LENOIRE, M., DOGANDŽIĆ, T., GOLDBERG, P., JACOBS, Z., MAIGROT, Y., MARTISIUS, N. L., MILLER, C. E., RENDU, W., RICHARDS, M., SKINNER, M. M., STEELE, T. E., TALAMO, S. \& TEXIER, J.-P.

2013 Neandertals made the first specialized bone tools in Europe, PNAS 110/35, 14186-14190. DOI:10.1073/ pnas. 1302730110

\section{UTRILLA, P. \& MONTES, L.}

1987 La Cueva de Peña Miel. Estudio arqueológico, en UTRILLA, P. et al. La cueva de Peña Miel. Nieva de Cameros, La Rioja, Excavaciones Arqueológicas en España 154. 23-84. Ministerio de Cultura. Madrid.

VALENSI, P. \& PSATHI, E.

2004 Faunal Exploitation during the Middle Palaeolithic in south-eastern France and north-western Italy. International Journal of Osteoarchaeology 14/3-4, 256-272. DOI:10.1002/oa.760.

\section{VEGA DE SELLA, C. DE LA}

1921 El Paleolítico de Cueva Morín (Santander) y notas para la climatología del Cuaternario, Memoria n 29. C.I.P.P. Madrid.

\section{VINCENT, A.}

1993 L'outillage osseux au Paléolithique moyen: une nouvelle approche. Tesis Doctoral. Université de Paris X. Paris.

\section{YRAVEDRA, J. \& GÓMEZ CASTANEDO, A.}

2011 Análisis de los procesos tafonómicos de Cueva Morín. Primeros resultados de un estudio necesario. Zephyrus $67,69-90$. 
